\title{
STRESS-STRAIN MODEL STUDY \\ OF FERROUS TAILING CONCRETE SHORT COLUMN RESTRAINT BY HOOPING
}

\author{
Sujuan LI \\ Hongzhen KANG* \\ Civil Engineering College, Tangshan University, Tangshan, Hebei 063000, China
}

\begin{abstract}
This study analyzed the stress-strain curve of stirrup restraint ferrous tailing concrete by test and theoretical analysis. Twenty short column in strength grade 5 are used in the test with WC30, WC35, WC40, WC45 and WC50. The stress-strain data is achieved after the axial compression behavior test. It is found from the stress-strain curve that the stress-strain relationship is similar with natural sand concrete. Moreover, the whole stress-strain curve equation of stirrup restraint ferrous tailing concrete is put forward. The calculation results show that the data calculating by the equation are in good agreement with the experimental data.
\end{abstract}

Keywords: ferrous tailing, restraint concrete, short column, stress-strain model

\section{INTRODUCTION}

The natural sand is mainly used as fine aggregate of concrete at present. Natural sand is a kind of non-renewable resource, and it has caused poor resources and even serious consequences of soil erosion because of excessive exploitation of natural sand. At the same time, the number of abandoned tailings in China is also increasing year by year. Land resource was occupied by abandoned tailings, and the environment was destroyed. Ferrous tailing sand concrete was prepared by taking tailing sand as the fine aggregate. Material properties and working performance of ferrous tailing concrete is similar to ordinary concrete prepared by nature sand. In recent years the research of

\footnotetext{
* Corresponding author: sujuanmail@163.com (S.J. Li)
} 
material properties of tailings sand concrete have been achieved (Hu 2014; Wang et al. 2015; Kang et al. 2015; Wang et al. 2015). But there are few studies on the properties of ferrous tailing sand short columns applied axial compression, especially the column which is made of ferrous tailing sand instead of nature sand. So it is necessary to study the axial compressive behavior of concrete short columns with iron tailings, and it will promote the application of tailings concrete in engineering. Based on this, the test was developed to the axial compressive behavior of concrete short columns with iron tailings, and the stress strain was analysed in this paper.

\section{TEST CONDITION}

The raw materials used in this test: local iron tailings from Tangshan and Dunshi cement produced by Jidong Cement Company, China, were used. Experiments of tailings sand concrete restrained by stirrups applying axial compression were carried out. In order to obtain the stress and strain data of tailings sand concrete restrained by stirrups, specimens of WC30, WC35, WC40, WC45 and WC50 were selected in the test. The concrete were used to fabricate short column sample. HRB400 steel bar was

Table 1. List of specimen

\begin{tabular}{|c|c|c|c|}
\hline Specimen number & Strength grade & Characteristic value of stirrup $\lambda_{t}$ & Hooping \\
\hline ZW1-A & WC30 & 0.11 & $\$ 10 @ 210$ \\
\hline ZW1-B & WC30 & 0.18 & $\$ 10 @ 180$ \\
\hline ZW1-C & WC30 & 0.28 & $\$ 10 @ 120$ \\
\hline ZW1-D & WC30 & 0.37 & $\$ 10 @ 90$ \\
\hline ZW2-A & WC35 & 0.09 & $\$ 10 @ 210$ \\
\hline ZW2-B & WC35 & 0.20 & $\$ 10 @ 150$ \\
\hline ZW2-C & WC35 & 0.28 & $\$ 10 @ 100$ \\
\hline ZW2-D & WC35 & 0.40 & $\$ 10 @ 70$ \\
\hline ZW3-A & WC40 & 0.12 & $\$ 10 @ 210$ \\
\hline ZW3-B & WC40 & 0.19 & $\$ 10 @ 130$ \\
\hline ZW3-C & WC40 & 0.27 & $\$ 10 @ 90$ \\
\hline ZW3-D & WC40 & 0.35 & $\$ 10 @ 70$ \\
\hline ZW4-A & WC45 & 0.11 & $\$ 10,210$ \\
\hline ZW4-B & WC45 & 0.18 & $\$ 10 @ 80$ \\
\hline ZW4-C & WC45 & 0.28 & $\$ 10 @ 60$ \\
\hline ZW4-D & WC45 & 0.37 & $\$ 10 @ 210$ \\
\hline ZW5-A & WC50 & 0.09 & $\$ 10 @ 100$ \\
\hline ZW5-B & WC50 & 0.20 & $\$ 10 @ 70$ \\
\hline ZW5-C & WC50 & 0.28 & \\
\hline ZW5-D & WC50 & 0.40 & \\
\hline & & & \\
\hline & & & $\$ 100$ \\
\hline
\end{tabular}


used for short column reinforcement. Two kinds of longitudinal forced reinforcement and stirrup were configured in the column. 1216 longitudinal reinforcements with $2.79 \%$ reinforcement percentage were used in each column. The diameter of stirrup was $10 \mathrm{~mm}$. For each strength grade concrete, 4 short columns with different characteristic value of stirrup were produced. The specimen size was $300 \times 300 \times 1200 \mathrm{~mm}$. The thickness of concrete cover of the sample was $15 \mathrm{~mm}$. In order to prevent concrete crushing at both ends, a ring of steel plate hoops with a width of $100 \mathrm{~mm}$ and a thickness of $3 \mathrm{~mm}$ was wrapped at each end of the column. The details of specimen preparation are shown in Table 1.

The test was carried out in the structural laboratory of the Civil Engineering College of Tangshan University. The long column testing machine with the pressure of $10000 \mathrm{kN}$ which was produced by Jinan Sanyue Testing Instrument Co. Ltd. was used for loading. In order to obtain the data of the descending stage of stress-strain curve conveniently, belleville springs rigid element was set at the four corners of the specimen in the experiment. The test loading was carried out in accordance with Standard for Test Method of Mechanical Properties on Ordinary Concrete GB50081-2002 (2002).

In this test, there were two failure modes of reinforced concrete short columns under axial pressure. The first failure mode was located between $1 / 2$ and $2 / 3$ of the column height. Several vertical cracks at the length of 5-10 cm appeared on the surface of the short column before the destruction, then the cracks penetrated transversely, the concrete protective layer gradually peeled off, and the longitudinal reinforcement protruded outward in the shape of "lantern". The concrete in the core area was crushed, and the short column was damaged. The second kind of failure was located between $1 / 3 \sim 2 / 3$ of the column height. Before the failure of the short column, there were several small vertical cracks at $1 / 3$ and $2 / 3$ of the high surface of the column. Then the cracks ran through obliquely. The concrete protective layer at the oblique cracks spalled, the steel bar buckled, and the upper and lower parts of the oblique cracks slightly dislocated. The angle between the inclined crack and horizontal plane was about 70 degrees. Longitudinal bars usually failed to yield, and the dislocation of longitudinal bars led to the dislocation of stirrups in the plane. Finally, concrete in the core area was crushed and specimens were damaged.

Processing the test data, the stress-strain curve can be drawn. The curve of specimen WC40 is shown in Fig. 1. It was found that the stress-strain curve of stirrup confined tailings concrete was similar to that of the ordinary concrete prepared by nature sand.

\section{STRESS-STRAIN MODEL OF CONCRETE WITH COMPRESSION RESTRAINT BY STIRRUP}

Stress-strain curve is the basis to study the bearing capacity and deformation of concrete members. For a long time, many scholars have devoted themselves to the study 
of the complete stress-strain curve of concrete. They have put forward many kinds of complete curve equations for core concrete confined by stirrup. Stages of ascending and descending were contained in these equations.

\subsection{EQUATION SUGGESTED BY THE CODE}

The equation, similar to the equation of plain concrete is used as the stress-strain model of restraint concrete in the Code for Design of Concrete Structure GB50010-2010 (2010):

$$
y=\left\{\begin{array}{c}
\alpha_{a} x+\left(3-2 \alpha_{a}\right) x^{2}+\left(\alpha_{a}-2\right) x^{3}, \quad 0 \leq x<1 \\
\frac{x}{\alpha_{d}(x-1)^{2}+x}, \quad x \geq 1
\end{array} .\right.
$$

The difference lies in the parameter values in the equation:

$$
x=\varepsilon / \varepsilon_{c c}, \quad y=\sigma / f_{c c} .
$$

The parameters of ascending curve can be determined by the following formula:

$$
\alpha_{a}=2.4-0.0125 f_{c c} .
$$

The parameters of descending curve can be determined by the following formula:

$$
\alpha_{d}=0.157 f_{c c}^{0.785}-0.905,
$$

where $f_{c c}$ stands for the peak value of confined concrete in the core zone and $\varepsilon_{c c}$ stands for the strain corresponding to peak stress.

\subsection{EQUATION TO STIRRUP CONSTRAINT CONCRETE}

Professor Qian Jiaru put forward the curve equation of the descending curve containing the characteristic value of stirrup to introduce the effect of stirrups on concrete in core zone:

$$
y=\left\{\begin{array}{cc}
\beta x+(3-2 \beta) x^{2}+(\beta-2) x^{3}, & 0 \leq x<1 \\
\frac{x}{\left(1-0.87 \lambda_{v}^{0.2}\right) \gamma(x-1)^{2}+x}, & x \geq 1
\end{array} .\right.
$$

The two parameters in Eq. (2) can be calculated by the following equation:

$$
\beta=2.4-0.01 f_{c u}, \quad \gamma=0.132 f_{c u}^{0.785}-0.905 .
$$


$\lambda_{v}$ represents the characteristic value of stirrup, and $f_{c u}$ represents the characteristic value of cubic concrete compressive strength.

\subsection{THE EQUATION IN THIS PAPER}

It was found from the test data that the stress-strain characteristics of the concrete confined by stirrups were similar to those of the natural sand concrete. Therefore the equation formally with the equation proposed by Professor Qian Jiaru was used in this paper. Then the stress-strain curve model of confined concrete with iron tailings sand can be achieved. After regression analysis of stress and strain data of test confined concrete, the suggested equation of concrete curve of tailings sand confined by stirrups was obtained:

$$
y=\left\{\begin{array}{lc}
c x+(3-2 c) x^{2}+(c-2) x^{3}, & 0 \leq x<1 \\
\frac{x}{\left(1-0.53 \lambda_{v}^{0.33}\right) d(x-1)^{2}+x}, & x \geq 1
\end{array} .\right.
$$

The two parameters in Eq. (3) can be calculated by the following equation:

$$
c=2.4-0.0224 f_{c u}, \quad d=0.132 f_{c u}^{0.785}-0.905 .
$$

\section{COMPARISON OF STRESS-STRAIN MODEL}

In order to compare the accuracy of the above three stress-strain models, the three models were used to calculate WC40. The calculation results and the test data are shown in Fig. 1.

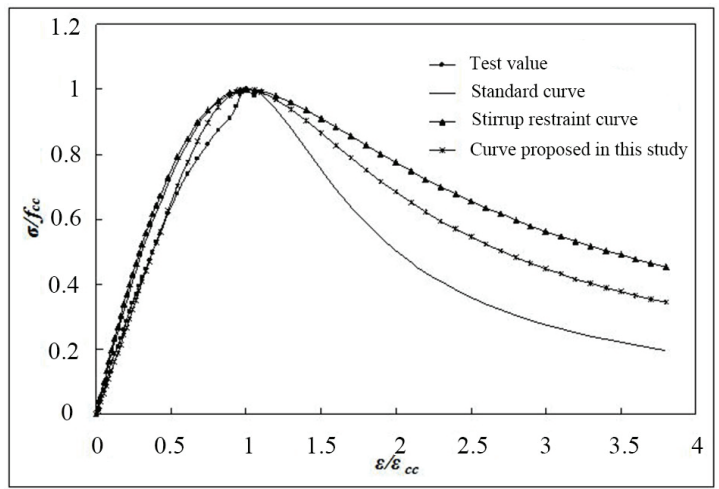

(a) Specimen ZW3-A 


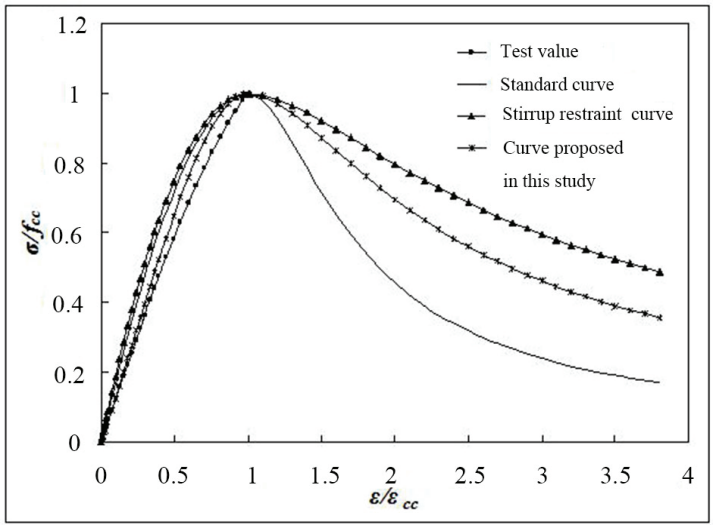

(b) Specimen ZW3-B

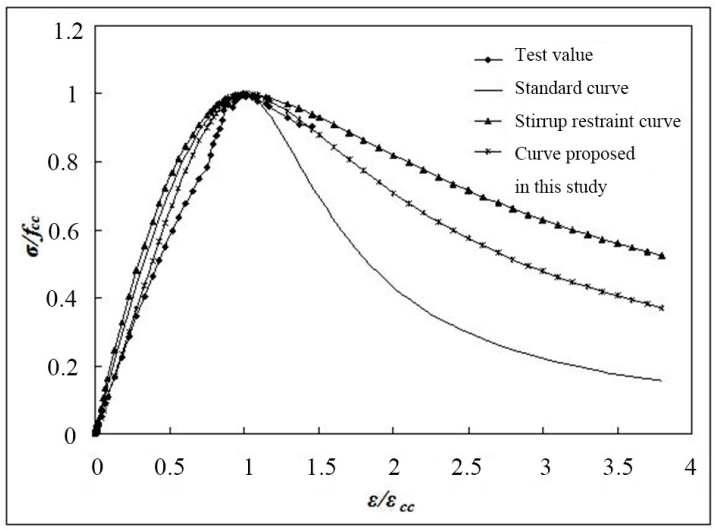

(c) Specimen ZW3-C

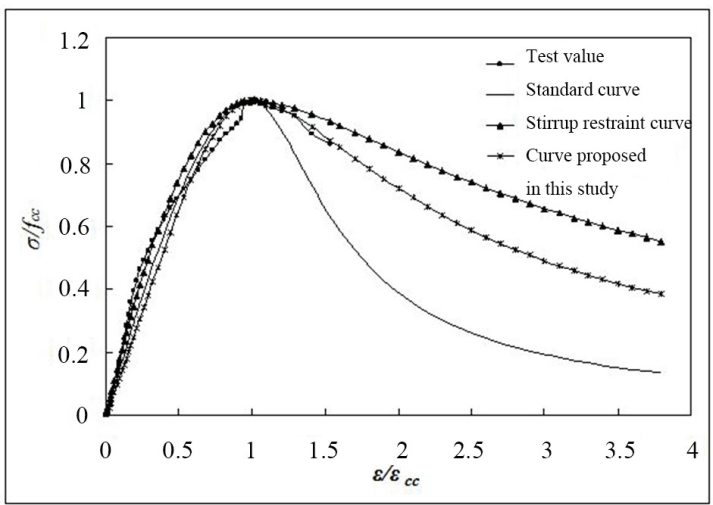

(d) Specimen ZW3-D

Fig. 1. Stress-strain curve of concrete restraint of WC40 
The comparison between the calculated results and the test curves of WC40 concrete confined by stirrups which used different stress-strain curve models is shown in Fig. 1. It was seen from Fig. 1 that the calculation result of the curve equation was more consistent with the test value. It also can be seen that the rising part of the three curve models were more similar, but the falling part were different. The stirrup restraint curve model showed the best ductility, while the curve model proposed by Standard for Test Method of Mechanical Properties on Ordinary Concrete showed the worst. Moreover the proposed curve was the closest to the test value. It was because that the stirrup restraint curve model constrained the parameter of characteristic value of stirrup and the advantageous restraint effect of stirrup was considered.

\section{CONCLUSION}

In this paper, the axial compression performance test of reinforced concrete short columns prepared by iron tailings concrete was carried out. According to the experimental data, the stress-strain curve of ferrous tailing concrete were obtained. Combining experimental data with theoretical analysis, the conclusion can be summarized as follows:

The stress-strain characteristics of stirrup confined tailings concrete column is similar to natural sand concrete;

Because of stirrup restraining, the stress-strain curves become fuller, which shows the better ductility of tailings sand concrete restraint by stirrup.

The calculation of the stress-strain equation is in good agreement with the experimental data to the tailings sand concrete column of WC40 used in the test.

\section{ACKNOWLEDGEMENTS}

This study was supported by National Natural Science Foundation Project (51378331) and Hebei Natural Science Foundation Project (E2016105062).

\section{REFERENCES}

HU X.L., 2014, Test study of permeability resistance of ferrous tailing concrete, Hebei United University.

HUANG S.W., LI Y.Y., CHENG L., YAN S., 2007, Preparation of burning and steam curing free bricks from Meishan iron ore tailings, Metal Mine, No. 4, 81-84.

KANG H.Z., ZHANG K., MA W.H., MENG Q.J., 2015, Experimental study on compressive stress-strain curves of ferrous tailings concrete, Journal of Building Structures, Vol. 12, 373-378.

Ministry of Development of the People's Republic of China, 2002, GB 50010-2010 Standard for test method of mechanical properties on ordinary concrete, Beijing, China Architecture and Building Press, 14.

Ministry of Housing and Urban-Rural Development of the People's Republic of China, 2010, GB 50010-2010 code for design of concrete structures, Beijing: China Architecture and Building Press, 42. 
WANG G.Q., KANG H.Z., HAN J.Q., 2015, Strength and preparation of ferrous tailing concrete, Journal of Hebei United University (Natural Science Edition), Vol. 4, 106-110.

WANG Q.W., ZHANG Y.K., KANG H.Z., DONG L., 2015, Experimental research on bond behavior between deformed bars and ferrous mill tailing concrete, Xi'an Univ. of Arch. and Tech. (Natural Science Edition), Vol. 12, 830-833. 